\title{
PROPOSTA DE IMPLEMENTAÇÃO DE POLÍTICAS MOTIVACIONAIS PARA CONTRIBUIR COM O NÍVEL DE SERVIÇO PRESTADO NAS ATIVIDADES COTIDIANAS DE UM RESTAURANTE: ESTUDO DE CASO
}

\author{
ARTIGO ORIGINAL \\ MONTEIRO, Elane Peixoto ${ }^{1}$ \\ RIBEIRO, Ingridy Samyra Kelle ${ }^{2}$ \\ SILVA, Rossinei Mariano da ${ }^{3}$ \\ ROBERTO, José Carlos Alves ${ }^{4}$
}

MONTEIRO, Elane Peixoto. Et al. Proposta de implementação de políticas motivacionais para contribuir com o nível de serviço prestado nas atividades cotidianas de um restaurante: Estudo de caso. Revista Científica Multidisciplinar Núcleo do Conhecimento. Ano 05, Ed. 11, Vol. 07, pp. 05-24. Novembro de 2020. ISSN: 2448-0959, Link de acesso: https://www.nucleodoconhecimento.com.br/administracao/politicasmotivacionais

\footnotetext{
${ }^{1}$ Graduanda do curso de administração do Centro Universitário FAMETRO.

${ }^{2}$ Graduanda do curso de administração do Centro Universitário FAMETRO.

${ }^{3}$ Graduando do curso de administração do Centro Universitário FAMETRO.

${ }^{4}$ Orientador. Mestrado profissional em Engenharia de produção. Especialização em Gestão em Logística empresarial. Graduação em Administração com Ênfase em Marketing.
} 


\section{RESUMO}

Diante das necessidades atuais com falta de suporte no desenvolvimento profissional dos colaboradores de contribuir com o crescimento e aprimoramento, a falta de motivação para criar um clima confortável para gestor e colaborador, aspectos importante que precisam ser aprimorados. O presente artigo tem o desígnio propor implementação de planos de capacitação e programas de políticas motivacionais para contribuir com a melhoria do nível de serviço prestado aos colaboradores do Restaurante Palhoça Ltda. Com base na pesquisa realizada na primeira etapa do diagnóstico organizacional, identificou-se que a área de recursos humanos é a mais crítica pela falta de capacitação e motivação dos colaboradores e ausência de planos de benefícios. A pesquisa teve como objetivo: Implementar políticas motivacionais para aumentar a harmonia e o nível de serviço prestado pelos colaboradores, nos objetivos específicos: Identificar por que os colaboradores estão desmotivados, analisar a influência da motivação como fator de mudança, analisar como pode melhorar o clima organizacional e os benefícios. A metodologia da pesquisa foi exploratória, explicativa e intervencionista, e quanto aos meios foi bibliográfica e pesquisa de campo. Foi utilizada a ferramenta $5 \mathrm{~W} 2 \mathrm{H}$ como proposta nas ações interventivas. O resultado é aumentar a produtividade, evitar a rotatividade, minimizar as possibilidades de desmotivação, sem deixar de considerar a sobrevivência da organização.

Palavras-Chave: Recurso Humano, capacitação e motivação.

\section{INTRODUÇÃO}

Este artigo refere-se ao estudo de caso que visa investigar um dado fenômeno dentro do Restaurante Palhoça Ltda, por meio de entrevista, analise documental e observações, tendo como intuito selecionar as principais ferramentas e tecnologias que sejam uteis e eficazes, para assim, ajudar na solução da falta de motivação ente os colaboradores para assim melhorar o nível de serviço prestado pelos mesmos. 
Perante o atual contexto de organização, a motivação passou a ser considerada como um dos principais fatores associados a produtividade e a qualidade no trabalho, dado que as instituições começaram a perceber a importância das pessoas que trabalham nela, como um diferencial competitivo.

Diante do exposto, o presente estudo teve como objetivos: Implementar programas de políticas motivacionais dentro do restaurante para aumentar a harmonia e o nível de serviço prestado dos colaboradores, já nos objetivos específicos: Identificar por que os colaboradores estão desmotivados, analisar a influência da motivação como fator de mudança, analisar como se pode melhorar clima organizacional por meio de capacitação e propor planos de motivação e benefícios para os colaboradores.

Este trabalho, quanto aos meios foi baseado em pesquisa de campo como visitas in loco, entrevistas, análise documental e observações, com intuito de organizar e sintetizar todas as informações que darão suporte a construção de um proposta efetivamente relevante. No decorrer do trabalho serão abordados temas relevantes para entendimento da importância da motivação como: definição da motivação, definição de serviço, definição de produtividade, conceito de treinamento, materiais e métodos utilizados, fluxograma como proposta de melhora e por fim resultados e discussões.

O tema deste artigo facilita que sejam identificados alguns problemas do dia a dia na organização. Facilitando a percepção da realidade organizacional de uma determinada empresa e assim definir de maneira mais objetiva as estratégias da organização. Portanto a motivação como uma ferramenta importante para o desenvolvimento das potencialidades dos colaboradores e diante da necessidade de estudos sobre esta temática, espera-se discutir à importância da utilização de políticas motivacionais, visando melhores relacionamentos interpessoais na equipe culminando em uma assistência de qualidade aos seus clientes. 


\section{REVISÃO BIBLIOGRÁFICA}

Dentro da abordagem da administração, cada vez mais as organizações enxergam seu capital humano como peça-chave para o sucesso e buscam conciliar a administração de recursos humanos como potencialização do desempenho dos integrantes da empresa, otimizando assim sua própria vantagem competitiva.

De acordo com Azevedo (2016) A revisão da literatura é sempre responsável por definir um panorama da literatura a respeito do tema escolhido, apresentando as principais abordagens das teorias acumuladas sobre uma temática, oferecendo assim, um claro e definido alinhamento com os objetivos da pesquisa.

A Fundamentação teórica apresenta as referências nas quais se baseia a pesquisa, o conjunto de conceitos, categorias e constructos abstratos que constituem o arcabouço teórico. Essas fontes de consulta podem ser obras publicadas, livros, monografias, periódicos especializados e documentos e registros existentes em institutos de pesquisa.

\subsection{DEFINIÇÃO DE MOTIVAÇÃO}

Bem como a sociedade, o perfil profissional modifica-se ao longo do tempo. Antes, atribuir um bom salário era sinônimo de motivação. No entanto, atualmente, é necessário que a organização esteja preparada para investir em outras ações, a fim de garantir a motivação no trabalho.

Conforme afirma Wagner e Hollenbeck (2020, p.108) "motivação se refere à energia que uma pessoa está disposta a dedicar a uma tarefa".

Deste modo, quando uma pessoa é motivada, ela tende a fazer o melhor para alcançar seus objetivos, bem como se torna capaz de criar novas estratégia para conduzir de maneira eficaz os imprevistos. A motivação tem a capacidade de mover resultados, cumprir metas, atingir objetivos e criar facilitadores emocionais para driblar os dificultadores do dia a dia. 


\subsubsection{POLÍTICAS MOTIVACIONAIS}

Percebeu-se que os tipos de políticas motivacionais que costumam ser aplicadas correspondem aos fatores intrínsecos que visam à autovalorização e auto realização dos indivíduos nas tarefas que executam. Manter a equipe de trabalho motivada é um desafio, agora se for estudado e adotando estratégias coerentes com a realidade da empresa, pode vir a alçar grandes resultados.

Como explica Jones e George (2012, p.275) "A motivação pode ser definida como o conjunto das forças psicológicas que determinam a direção do comportamento de uma pessoa em uma organização e seus níveis de esforço e de persistência diante de obstáculos".

Para isso destacam-se alguns exemplo de políticas motivacionais recomendadas.

- Estabelecer objetivos ambiciosos para todo a respeito de seu desempenho.

- Periodicamente dar feedback ao colaborado a respeito de seu desempenho na empresa.

- Agir preventivamente, indicando pontos a corrigir ou melhorar.

- Obter compromisso dos colaboradores a respeito do desempenho esperado pela empresa.

- Avaliar o desempenho com isenção e imparcialidade.

\subsubsection{ESTRATÉGIAS MOTIVACIONAIS}

$\mathrm{Na}$ tentativa de compreender esta questão de estratégia motivacionais, muitos pesquisadores têm procurado descrever as relações entre estratégias e constructos motivacionais, pois embora muitos colaboradores possuam capacidades autor regulatórias, nem sempre se envolvem em atividades direcionadas a este fim. Ressalta-se que essa atividade requer esforço e, portanto, deve estar relacionada ao interesse ou necessidade do colaborador. 
Para Busarello (2016, p.12) "Ambientes gamificados podem contribuir para criação de contextos motivacionais com base em desafios emocionantes, recompensas pela dedicação e eficiência".

Motivar é, de certa forma, é uma arte, existe várias maneiras de se fazer, todas elas com vantagens e desvantagens, cabe ao líder ou gestor analisar e estudar qual é a melhor estratégia ou ferramenta para sua aplicabilidade e adaptabilidade que de fato seja concebida para melhorar a motivação dos colaboradores para que eles trabalhem satisfeitos e, consequentemente, melhor.

\subsubsection{PLANOS E BENEFÍ́CIOS}

É uma forma de motivar os colaboradores a se empenharam com afinco no desenvolver das atividades com intuito de melhorar a produtividade do colaborador. Um plano bem elaborado e benefícios que supras as necessidades dos colaboradores, os deixando motivados para um bom desempenho nas atividades.

Conforme afirma Cioffi (2016, p. 47) "se refere ao plano de benefícios como uma forma de reter mão de obra, através do oferecimento de diferenciais como plano de saúde, previdência privada, seguro de vida, entre muitos outros".

As empresas podem oferecer alguns benefícios que são: vale-alimentação, valerefeição, planos de assistência médica e odontológica, orientação nutricional, programas de educação financeira, prática de esportes e exercícios, auxílio-despesas, vale-presente para premiar funcionários que atingem as metas, horas flexíveis, auxílio moradia, aluguel de apartamento, seguro de vida, farmácia e etc. Com intuito de ter o colaborador satisfeito com a empresa e assim refletindo no desempenho dos funcionários.

\subsection{DEFINIÇÃO DE SERVIÇO}

São atos, processos de atuações oferecidos ou coproduzidos por uma entidade ou pessoa, onde é apresentado para o cliente por meio de atividade para análise de solução de problema, reuniões com o cliente, para satisfazer o cliente. 
Segundo Marangoni (2015, p. 14) "Diferentes dos produtos, os serviços apresentam características peculiares, que impactam diretamente no modo como a empresa irá prestá-los".

Por isso o termo serviço pode ser visto, atualmente, como uma forma de aumentar a rentabilidade e a lucratividade das empresas, e também demonstrar o espírito empreendedor, fazendo a diferença com diversas implementações e juntos aos serviços aumentando a atividade operacional principal, elevando as receitas, onde seu papel e alcançar objetivos e deve ser mensurado com o mesmo rigor de produtos, pois os clientes não separam o que é produto do que serviço, um é complemento do outro.

\subsection{DEFINIÇÃO DE PRODUTIVIDADE}

Produtividade é uma relação entre duas variáveis. Sendo um referente aos recursos utilizados em um processo e outra referente aos resultados deste processo, ela é a chave para o foco, que nada mais é a canalização da capacidade da energia em uma única atividade. No entanto ela depende da eficácia e quanto da eficiência, pelo fato de obter resultados otimizados, com maior qualidade, quantidade velocidade e/ou menor custo.

De acordo com Daher (2017, p. 67) "A produtividade das organizações, para atingir seus objetivos, dependerá diretamente de uma série de elementos de atuação, tais como flexibilidade, velocidade, produtividade, custo, qualidade e confiabilidade".

O termo é visto e utilizado de muitas e variadas formas, no entanto, constatasse que não há consenso sobre a sua definição, que raramente é definida ou conceituada de maneira formal, mesmo por quem o utiliza. Assim como, os conceitos das palavras desempenho, produção e produtividade são comumente confundidos. 


\subsection{CONCEITO DE TREINAMENTO}

O treinamento são práticas que estão diretamente associadas à qualificação e melhoria contínua do desempenho e crescimento profissional dos funcionários dentro dos seus cargos.

Para Bateman (2012, p. 168) "As empresas investem em treinamentos para melhorar o desempenho individual e a produtividade organizacional".

É um processo sistemático para promover a aquisição de habilidades, regras, conceitos e atitudes que busquem melhorar a adequação entre as características dos empregados e as exigências dos papéis funcionais, podem ser considerado um esforço planejado e organizado, em especial para auxiliar os indivíduos a desenvolverem suas capacidades.

Desta forma, o treinamento motivacional nada mais é do que tipo de treinamento e desenvolvimento que tem o objetivo de aumentar o engajamento e interesse doa colaboradores na organização.

Sendo assim, treinamento motivacional pode envolver:

- Palestras Motivacionais

- Dinâmicas em grupo

- Acompanhamento através de feedbacks

- Convenções

- Momentos de Confraternização

- E muito mais

Dentre os principais benéficos do treinamento motivacional são eles:

- Melhorar a produtividade e a qualidade do trabalho

- Diminui a rotatividade

- Melhorar o clima organizacional

- Aumentar o envolvimento dos colaboradores nas tomadas de decisão 


\subsubsection{ENDOMARKETING}

O endomarketing busca identificar pontos de melhorias para o público interno, a fim de transformar o ambiente de trabalho em um local inspirador e cada vez mais humano, sendo seu principal objetivo integrar as relações entre a empresa e os seus funcionários por meio de uma comunicação uniforme e que compartilhe com todos a cultura da empresa.

Como explica Bueno (2013, p. 23) "Utilizando o endomarketing, podemos tornar os colaboradores comprometidos e que percebam que cada um, em seu respectivo trabalho é importante para o crescimento da empresa".

Em síntese, a ideia máxima é a de total integração ao Marketing, uma vez que o publico interno é incorporado no processo de desenvolvimento do produto/serviço, e suas habilidades são valorizadas e aprimoradas, criando um ambiente no qual todos possam trabalhar com o mesmo foco, procurando motivar os funcionários/colaboradores, fazendo com que eles realmente se sintam como parte importante dentro da empresa.

\subsubsection{AVALIAÇÃO DO DESEMPENHO}

Consiste em uma análise sistemática do desempenho de cada funcionário, a partir do cumprimento de suas funções, das metas e dos resultados a serem alcançados, em conjunto com o seu potencial de desenvolvimento, que é capaz de gerar muitos efeitos positivos na empresa, sendo uma ferramenta para medir a performance dos indivíduos e melhorar os resultados coletivos e individuais.

Conforme afirma Pontes (2016, p. 26) "É o sopro de vida da organização, e sem a sua existência o planejamento ou as estratégias organizacionais não farão o menor sentido, porque o instrumento é capaz de trazer a reunião da sala pro dia a dia do funcionário".

É de fundamental importância para alcançar as metas e fornecer ao setor de recursos humanos dados importantes sobre a atuação de cada profissional, subsidiando 
decisões importantes junto aos gestores. Dessa forma, é possível capacitar talentos e propor planos de desenvolvimento de acordo com os feedbacks, estimulando um trabalho cada vez melhor.

Por tanto destacam-se, 8 tipos de modelos de avaliação de desempenho.

- Auto avaliação

- Avaliação de desempenho da equipe

- Escala gráfica

- 360 graus

- Escolha forçada

- Avaliação de desempenho por competências

- Metas e resultados

- Avaliação de desempenho do líder

\subsubsection{NET PROMOTER SCORE}

É uma métrica utilizada para medir a satisfação dos clientes de uma empresa. No entanto, é uma excelente ferramenta para ser utilizada também com o público interno de uma organização. A partir de uma única pergunta, "em uma escalada de 0 a 10, quanto você nos indicaria para um amigo", o RH pode avaliar a satisfação dos colaboradores. Sendo zero o mesmo que "de jeito nenhum" e 10 "com certeza".

Para Lara et al (2016) essas respostas possibilitam às empresas o acompanhamento dos seus índices de promotores e detratores, proporcionando uma média clara a organização através do ponto de vista do cliente. A partir das notas atribuídas pelos clientes de 0 a 10, há três formas de classificação, sendo: as notas de zero a seis indicadas por clientes detratores; as notas de sete e oito pelos clientes considerados neutros; e as notas de nove a dez correspondem aos clientes promotores.

Assim, é possível identificar o grau de lealdade do time com a empresa, observando o nível de satisfação de cada um. 


\section{MATERIAIS E MÉTODOS}

A definição dessa abordagem e a seleção dos métodos e técnicas de pesquisa são realizadas a partir da formulação do problema de pesquisa, ou seja, ainda em um nível estratégico, de natureza teórico conceitual. É nesse nível que são identificados, por exemplo as lacunas, permitindo assim um aprofundamento da literatura.

Segundo Cauchick et al (2012, p.132) "Uma abordagem metodológica adequada de pesquisa compreende diferentes níveis de abrangência e profundidade".

\subsection{PROCEDIMENTOS METODOLÓGICOS}

Como explica Libório e Terra (2015, p. 40) "A metodologia de pesquisa varia conforme o tipo de trabalho escolhido pelo pesquisador, o tipo de área do conhecimento da qual faz parte e o tema destacado para o trabalho".

Deste modo esse trabalho é um estudo de caso de caráter empírico que visa investigar um dado fenômeno dentro do Restaurante Palhoça Ltda, por meio de entrevista, analise documental e observações, tendo como objetivo selecionar as principais ferramentas e tecnologias que sejam uteis e eficazes, para assim, ajudar na solução da melhoria do nível de serviço prestado.

\subsubsection{QUANTO A NATUREZA}

De acordo com Pereira et al (2018, p.67) "Os métodos qualitativos são aqueles nos quais é importante a interpretação por parte do pesquisador com suas opiniões sobre o fenômeno em estudo. Neles a coleta de dados muitas vezes ocorre por meio de entrevistas com questões abertas".

A natureza utilizada no projeto é pesquisa aplicada é qualitativa, devido realização de visitas in loco, análise de dados por meio entrevista com colaboradores, busca de informações através de opiniões dos gestores da organização, análise por meio de observação direta e por fim propõe solução. 


\subsubsection{QUANTOS AOS FINS}

A pesquisa científica deve ser classificada quanto aos seus objetivos e está classificação dependerá do objeto, metodologia empregada e problema de pesquisa. Isso quer dizer que, não pode ser escolhido de forma aleatória, deve ter um fim específico.

Para Correa e Costa (2012) a Pesquisa Exploratória é fase preliminar do trabalho científico, com intuito de explorar mais informações do assunto a ser estudado, determinar o tema que será pesquisado, traçar os objetivos, formular ou não hipóteses, ou descobrir um novo tipo de perspectiva para o assunto investigado.

O estudo de caso em evidência, se caracteriza como exploratória, porque tem foco no problema, apontando hipótese, é flexível e envolve levantamento de dados, entrevista e bibliografia, a fim de que a análise seja realizada com maior precisão

\subsubsection{QUANTOS AOS MEIOS}

Segundo Vergara (2016) a pesquisa de campo trata-se de uma investigação empírica realizada no local da manifestação do fenômeno ou no local que dispõe elementos para explicá-lo. Podendo incluir entrevistas, aplicação de questionários, testes e observação participante ou não.

Exemplo: levantar com os usuários do Banco $X$ a percepção que têm sobre o atendimento ao cliente.

Este trabalho, quanto aos meios será baseado em pesquisa de campo como visitas in loco, entrevistas, análise documental e observações, com intuito de organizar e sintetizar todas as informações que darão suporte a construção de um proposta efetivamente relevante. 


\subsection{CARACTERIZAÇÕES DA EMPRESA}

O Restaurante Palhoça Ltda está situado na Rua Simões, no 300, no bairro Santo Agostinho na Cidade de Manaus-AM. Foi fundado como um famoso ambiente dançante nos anos 1970, reconhecido pela arquitetura marcante e pela inovação em seus pratos. Retornou à lista de opções amantes da culinária, na capital amazonense em 2018 no ramo de restaurante regional, o diferencial de um restaurante amazônico, além dos peixes amazônicos que todo restaurante tem, é oferecido também carnes, 'steaks' como o filé Wellington, pato, carneiro e vários outros. A organização conta com uma equipe altamente qualificada, com o objetivo de oferecer, produtos com alta qualidade e um atendimento especializado de forma satisfatória.

O local, além de restaurante é também cafeteria, a proposta é servir a todos os gostos desde o regional, passando pelo comum até o sofisticado. Uma das inovações do novo espaço é a área destinada ao co-working. $\mathrm{O}$ 'quadradinho de vidro' comporta de 40 a 50 pessoas e pode ser utilizado para eventos. As salas de trabalho compartilhado oferecem comodidade a empreendedores criativos, a intenção é que esse espaço contextualizasse a experiência.

O restaurante possui 18 colaboradores entre chefes de cozinhas, atendentes, auxiliar de caixa, garçons e auxiliar de serviços gerais. Portanto se enquadra no porte empresarial de empresa ME Microempresa, de acordo com a classificação do SEBRAE e da LC 123/2006.

\section{RESULTADOS E DISCUSSÕES}

Considerando as análises das informações coletadas na pesquisa do Diagnóstico Organizacional, foi confirmado que a empresa em estudo, apresenta pontos bastante relevância em todas suas áreas funcionais da organização, como é demonstrado no Gráfico 01: Média do Desempenho por área Funcional. 
Gráfico 1: Média do Desempenho por área funcional

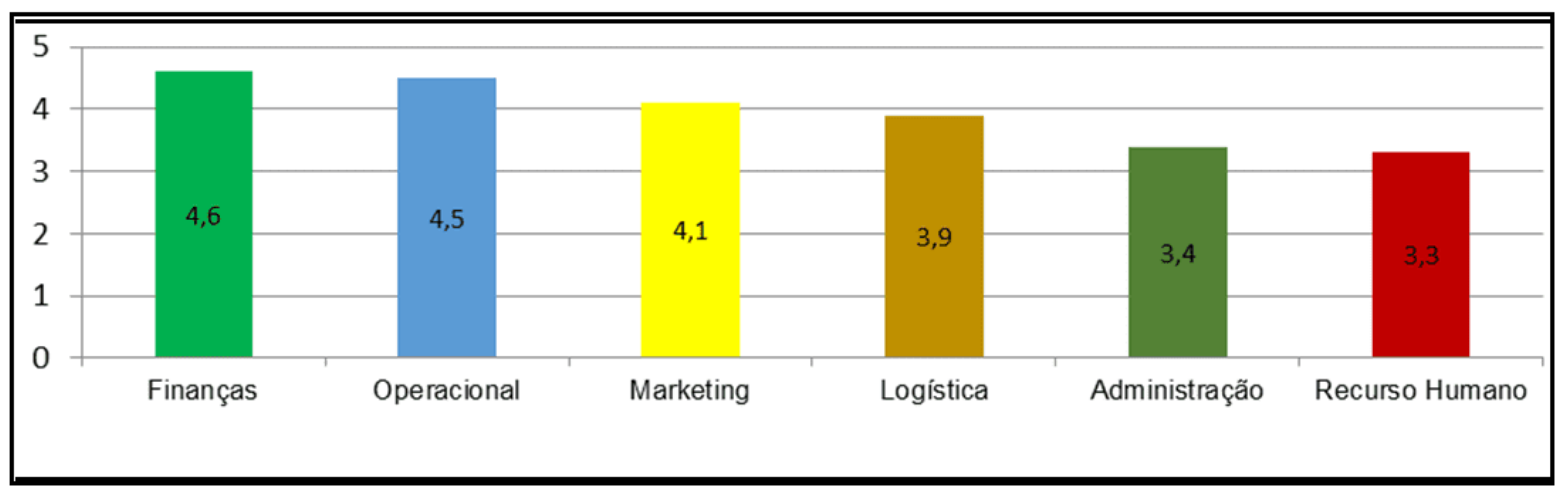

Fonte: Elaborado pela equipe com base em pesquisa de campo - 2020.

Observa-se que a empresa tem a área de Finança como o melhor nível de desempenho; operacional, marketing e logística são áreas de desempenho médio. Já o Recurso Humano é constatado como a área mais crítica da organização, que exigem atenção máxima.

Quadro 1: Recursos Humanos

\begin{tabular}{|c|c|c|c|c|c|c|}
\hline \multicolumn{2}{|c|}{ Fatores Críticos } & 5 & 4 & 3 & 2 & 1 \\
\hline 1 & Índice de rotatividade ou turnover & & & X & & \\
\hline 2 & Investimento de treinamento para funcionários & $\mathrm{x}$ & & & & \\
\hline 3 & Índice de satisfação dos colaboradores & & & $\mathrm{x}$ & & \\
\hline 4 & Gestores capacitados e qualificados & & $\mathrm{x}$ & & & \\
\hline 5 & $\begin{array}{l}\text { Índice de satisfação dos colaboradores bem } \\
\text { motivados }\end{array}$ & & & & $\mathrm{x}$ & \\
\hline 6 & Plano de benefícios e bônus & & & & & $\mathrm{x}$ \\
\hline 7 & Renumeração adequada aos funcionários & & $\mathrm{x}$ & & & \\
\hline 8 & $\begin{array}{l}\text { Avaliação objetiva do desempenho dos } \\
\text { funcionários }\end{array}$ & & & $\mathrm{x}$ & & \\
\hline 9 & $\begin{array}{l}\text { Atividades de trabalho no restaurante de acordo } \\
\text { com normas e leis trabalhistas }\end{array}$ & & $\mathrm{x}$ & & & \\
\hline
\end{tabular}




\begin{tabular}{|l|l|l|l|l|l|l|}
\hline 10 & $\begin{array}{l}\text { Tratamento igualitário e respeitoso entre } \\
\text { proprietário e funcionários }\end{array}$ & & $x$ & & & \\
\hline Total & 5 & 16 & 9 & 2 & 1 \\
\hline Média por grau & 0,5 & 1,6 & 0,9 & 0,2 & 0,1 \\
\hline Desempenho da área $(\Sigma)$ & $\mathbf{3 , 3}$ & & & \\
\hline
\end{tabular}

* Sendo 5 valor máximo (ponto muito forte) e 1 valor mínimo (ponto muito fraco).

Fonte: Elaborado pela equipe, com base em pesquisa de campo, 2020.

Portanto os fatores mais críticos considerados e demonstrados no Quadro 01, são itens fundamentais e imprescindível na área de recurso humano no Restaurante Palhoça Ltda, que necessitam ser trabalhado Com intuito de melhorar a condução de seus processos bem como aumentar o engajamento e interesse de seus colaboradores, pois necessitam estar alinhados com a política organizacional, precisam estar bem treinados, com padrões estabelecidos e motivados para o alcance dos objetivos. Dessa forma a problemática da pesquisa é exatamente: Como implantar Políticas Motivacionais para contribuir com a melhoria do nível de serviço prestado pelos colaboradores?

\subsection{PLANEJAMENTO DAS AÇÕES}

Planejamento das ações consiste em organizar todos os passos, ter um cronograma de ações e disciplina para cumpri-los, é separar todas as etapas de elaboração da execução, obtendo assim um estudo mais detalhado e assertivo de todas as atividades necessárias para atingir um determinado objetivo.

Quadro 2: Ações Interventivas

\begin{tabular}{|l|l|l|l|l|}
\hline Item & Ação Interventiva & Procedente & Cronologia & Custo \\
\hline $\mathbf{1}$ & $\begin{array}{l}\text { Elaboração do plano de } \\
\text { capacitação profissional }\end{array}$ & Falta de treinamento & Dois dias & $R \$$ \\
\hline
\end{tabular}




\begin{tabular}{|c|c|c|c|c|}
\hline 2 & $\begin{array}{l}\text { Implantar ferramentas do } \\
\text { Endomarketing }\end{array}$ & $\begin{array}{l}\text { Colaboradores } \\
\text { desmotivados }\end{array}$ & Um dia & $\begin{array}{l}R \$ \\
500,00\end{array}$ \\
\hline 3 & $\begin{array}{l}\text { Implementação do plano de } \\
\text { incentivos e reconhecimento }\end{array}$ & $\begin{array}{l}\text { Falta de incentivos } \\
\text { para } \\
\text { colaboradores }\end{array}$ & Um dia & $\begin{array}{l}\mathrm{R} \$ \\
900,00\end{array}$ \\
\hline 4 & $\begin{array}{lr}\text { Implementação } & \text { de } \\
\text { comemorações } & \text { e } \\
\text { convenções } & \end{array}$ & $\begin{array}{ll}\text { Falta } & \text { de } \\
\text { programação } & \end{array}$ & Semestral & $\begin{array}{l}\mathrm{R} \$ \\
1.500,00\end{array}$ \\
\hline 5 & $\begin{array}{l}\text { Implementação da avaliação } \\
\text { do desempenho e repasse } \\
\text { do feedback }\end{array}$ & Falta de feedback & Um dia & $\begin{array}{l}\mathrm{R} \$ \\
500,00\end{array}$ \\
\hline 6 & $\begin{array}{l}\text { Implementar o Net Promoter } \\
\text { Score }\end{array}$ & $\begin{array}{l}\text { Falta de satisfação } \\
\text { dos colaboradores }\end{array}$ & Um dia & $\begin{array}{l}R \$ \\
400,00\end{array}$ \\
\hline \multicolumn{4}{|c|}{ Total } & $\begin{array}{l}R \$ \\
5.000,00\end{array}$ \\
\hline
\end{tabular}

Fonte: Elaborado pelos autores, 2020.

Devido a simplicidade e praticidade do $5 \mathrm{~W} 2 \mathrm{H}$, que pode ser aplicado nos mais diversos âmbitos, inclusive no dia a dia, optou-se por essa ferramenta como proposta de solução, onde cada etapa responde seis pontos fundamentais da execução e ajudam a garantir que nenhuma etapa ou atividade seja esquecida ou deixada de lado.

Segundo Arruda et al(2016), 5W2H é uma ferramenta bastante utilizada na implantação de melhoria nos processos das organizações, analisa os problemas e planeja as ações corretivas, com os seguintes questionamentos, que tem como origem as palavras em inglês, como: Why(Por quê?), What(O que?), Who (Quem?), When(Quando?), Where(Onde?), How(Como?) e How Much(Quanto?).

\subsubsection{ELABORAÇÃO DO PLANO DE CAPACITAÇÃO PROFISSIONAL}

Investir na capacitação profissional é importante para treinar e desenvolver habilidades técnicas dos colaboradores. Portanto, é fundamental investigar as 
necessidades da organização e criar programas de capacitação e desenvolvimento que atendam a essas demandas.

Para o Restaurante Palhoça Ltda, a capacitação se faz necessária para preparar o seu pessoal para realizar as atividades com eficiência e autonomia. Isso porque profissionais capacitados se sentem mais motivados em sua rotina, pois enxergam uma maior valorização do seu trabalho.

Quadro 3: 5w2h - Elaboração do plano de capacitação profissional

\begin{tabular}{|c|c|}
\hline & Elaboração do plano de capacitação profissional \\
\hline O que? & Capacitar os colaboradores \\
\hline Por quê? & $\begin{array}{l}\text { Para tornar os colaboradores mais motivados e comprometidos com a } \\
\text { organização }\end{array}$ \\
\hline Onde? & No Restaurante Palhoça \\
\hline Quando? & Primeira semana de dezembro de 2020 \\
\hline Quem? & Todos os colaboradores do Restaurante Palhoça \\
\hline Como? & $\begin{array}{l}\text { Contratando um profissional qualificado que possa aplicar cursos de } \\
\text { reciclagem e workshops }\end{array}$ \\
\hline Quanto? & $\mathrm{R} \$ 1.200,00$ \\
\hline
\end{tabular}

Fonte: Elaborado pelos autores, 2020

\subsubsection{IMPLANTAR FERRAMENTAS DO ENDOMARKETING}

Endomarketing, ou marketing interno, trata-se de ações estratégicas de marketing direcionadas ao público interno da empresa que tem como propósito fortalecer o relacionamento leal e harmônico entre organização e colaboradores, possibilitando o aumento da disposição, do envolvimento e do comprometimento dos funcionários com as metas desenvolvidas pela empresa que, consequentemente, acaba melhorando seu valor de mercado.

No Restaurante Palhoça Ltda, intuito dessa prática é transformar abordagens teóricas, como Missão, Visão e Valores, em práticas e resultados concretos, moldando o 
comportamento e mobilizando os colaboradores do Restaurante para refletir tais resultados para o público externo. É alinhar o pensamento dos colaboradores com os objetivos da organização por meio de estratégias e ações que aperfeiçoam e fortalecem este relacionamento, com o objetivo final também de otimizar os lucros da empresa.

Quadro 4: 5w2h - Implantar ferramentas do Endomarketing

Implantar ferramentas do Endomarketing

O que? Marketing Interno

Por quê? Para aumentar a satisfação do público interno da empresa

Onde? No Restaurante Palhoça

Quando? Primeira semana de dezembro de 2020

Quem? Todos os colaboradores do Restaurante Palhoça

Como? Aplicando pesquisa de clima organizacional com o apoio de uma empresa de consultoria externa

Quanto? $\mathrm{R} \$ 500,00$

Fonte: Elaborado pelos autores, 2020.

\subsubsection{IMPLEMENTAÇÃO DO PLANO DE INCENTIVOS}

O plano de incentivo pode ser entendido como um sistema de metas e recompensas, onde o objetivo é reconhecer, estimular e retribuir o comportamento, o engajamento e o desempenho dos colaboradores.

Conceder incentivos financeiros ou não financeiros aos trabalhadores. No primeiro caso, o colaborador recebe bonificações em dinheiro. Já no segundo, recebe viagens, folgas, passeios, prêmios, entre outras inúmeras formas de recompensas. O intuito é de suprir a necessidade do colaborador, buscando alinhar a sua satisfação com os interesses do Restaurante Palhoça Ltda. 
Quadro 5: 5w2h - Implementação do plano de incentivos

\begin{tabular}{|l|l|}
\hline \multicolumn{2}{|c|}{ Implementação do plano de incentivos } \\
\hline O que? & Incentivos \\
\hline Por quê? & Para que o colaborador se sinta motivado \\
\hline Onde? & No Restaurante palhoça \\
\hline Quando? & A partir dos proventos de dezembro \\
\hline Quem? & Todos os colaboradores \\
\hline Como? & $\begin{array}{l}\text { Concedendo um dia de folga por mês como prêmio por produtividade; } \\
\text { programa de prêmios como viagens e passeios }\end{array}$ \\
\hline Quanto? & $\mathrm{R} \$ 900,00$ \\
\hline
\end{tabular}

Fonte: Elaborado pelos autores, 2020

\subsubsection{IMPLEMENTAÇÃO DE COMEMORAÇÕES E CONVENÇÕES}

Por sua vez o plano de comemorações de convenções tem por objetivo incentivar os colaboradores através de eventos sociais onde busca-se a saúde psicossocial do colaborador.

Em todo caso as comemorações e convenções tem um papel crucial para motivar o colaborador. É um sistema onde o funcionário consegui liberar o estresse acumulado no período funcional e assim com as energias renovadas para uma nova jornada laboral.

Quadro 6: 5w2h - Implementação de comemorações e convenções

\begin{tabular}{|l|l|}
\hline \multicolumn{2}{|c|}{ Implementação de comemorações e convenções } \\
\hline O que? & Comemorações \\
\hline Por quê? & Para que o colaborador se sinta motivado \\
\hline Onde? & Paraiso 21 \\
\hline Quando? & A partir dos proventos de dezembro \\
\hline Quem? & Todos os colaboradores \\
\hline
\end{tabular}


Como? Será realizado um passeio como para o paraíso 21, onde será distribuído brindes para os colaboradores

Quanto? $R \$ 1.500,00$

Fonte: Elaborado pelos autores, 2020

\subsubsection{IMPLEMENTAÇÃO DA AVALIAÇÃO DO DESEMPENHO E REPASSE DO FEEDBACK}

A avaliação de desempenho é uma ferramenta do Recurso Humano para analisar a performance de um colaborador ou de um time inteiro. Avalia-se continuadamente 0 desempenho das pessoas, das coisas e dos objetos no mundo em que se vive, o que torna isso, um fato comum no dia-a-dia, onde para que se posa sobreviver em um ambiente global, altamente competitivo, as organizações exigem alto nível de desempenho de seus colaboradores onde a realização do feedback de forma incorreta pode resultar em desestímulos gerando um clima organizacional desconfortável.

Aplicado no Restaurante Palhoça, a avalição de desempenho tem por objetivo aperfeiçoar de maneira contínua os colaboradores, evidenciar os problemas de relacionamentos, demonstrar a evolução dos colaboradores, gerar motivação e satisfação no trabalho, propiciar a geração de aumentos salariais, informar aos colaboradores o seu desempenho no trabalho e sugerir mudanças necessárias, quanto aos comportamentos e atitudes, habilidades ou conhecimentos.

Quadro 7: 5w2h - Implementação da avaliação do desempenho e repasse do feedback

Implementação da avaliação do desempenho e repasse do feedback

O que? Avaliar os colaboradores

Por quê? Para Incentivar a prática da cultura do feedback

Onde? No Restaurante Palhoça

Quando? Segunda semana de novembro de 2020

Quem? Todos os colaboradores do Restaurante Palhoça 
Como? Com aplicação de questionário como instrumento de pesquisa de campo elaborado através de um especialista

Quanto? $\mathrm{R} \$ 500,00$

Fonte: Elaborado pelos autores, 2020

\subsubsection{IMPLEMENTAR O NET PROMOTER SCORE}

O net promoter score quem português significa pontuação liquida do promotor é muito usada nas empresas para avaliar o quanto os colaboradores estão satisfeitos como trabalho.

A avaliação é feita a partir da seguinte pergunta, "em uma escalda de 0 a 10, o quanto você nos indica para um amigo", desta forma medimos a satisfação onde a resposta for $0=$ totalmente insatisfeito e se for $10=$ muito satisfeito o que gera motivação para desenvolver suas atividades com afinco e presteza.

Quadro 8: 5w2h - Net Promoter Score

\begin{tabular}{|c|c|}
\hline \multicolumn{2}{|c|}{ Net Promoter Score } \\
\hline O que? & Pontuação liquida do promotor \\
\hline Por quê? & $\begin{array}{l}\text { Para avaliar o quanto os colaboradores estão motivados e satisfeitos } \\
\text { com o trabalho }\end{array}$ \\
\hline Onde? & No restaurante palhoça \\
\hline Quando? & A partir dos proventos de dezembro \\
\hline Quem? & Todos os colaboradores \\
\hline Como? & $\begin{array}{l}\text { Respondendo à pergunta: De } 0 \text { a } 10 \text { o quanto você indica a nossa } \\
\text { empresa para um amigo? }\end{array}$ \\
\hline Quanto? & $\mathrm{R} \$ 400,00$ \\
\hline
\end{tabular}

Fonte: Elaborado pelos autores, 2020. 


\subsection{FLUXOGRAMA COMO PROPOSTA DE MELHORIA}

Mediante análise dos dados da área de Recurso Humano no Restaurante, foi desenvolvido e sugerido um modelo de fluxograma. Com esse novo modelo se buscará aumentar a motivação dos colaboradores a fim de poder adequá-las da melhor forma possível, melhorando o seu desempenho e consequentemente o clima e a cultura organizacional.

Imagem 1: Fluxograma da Proposta de Melhoria

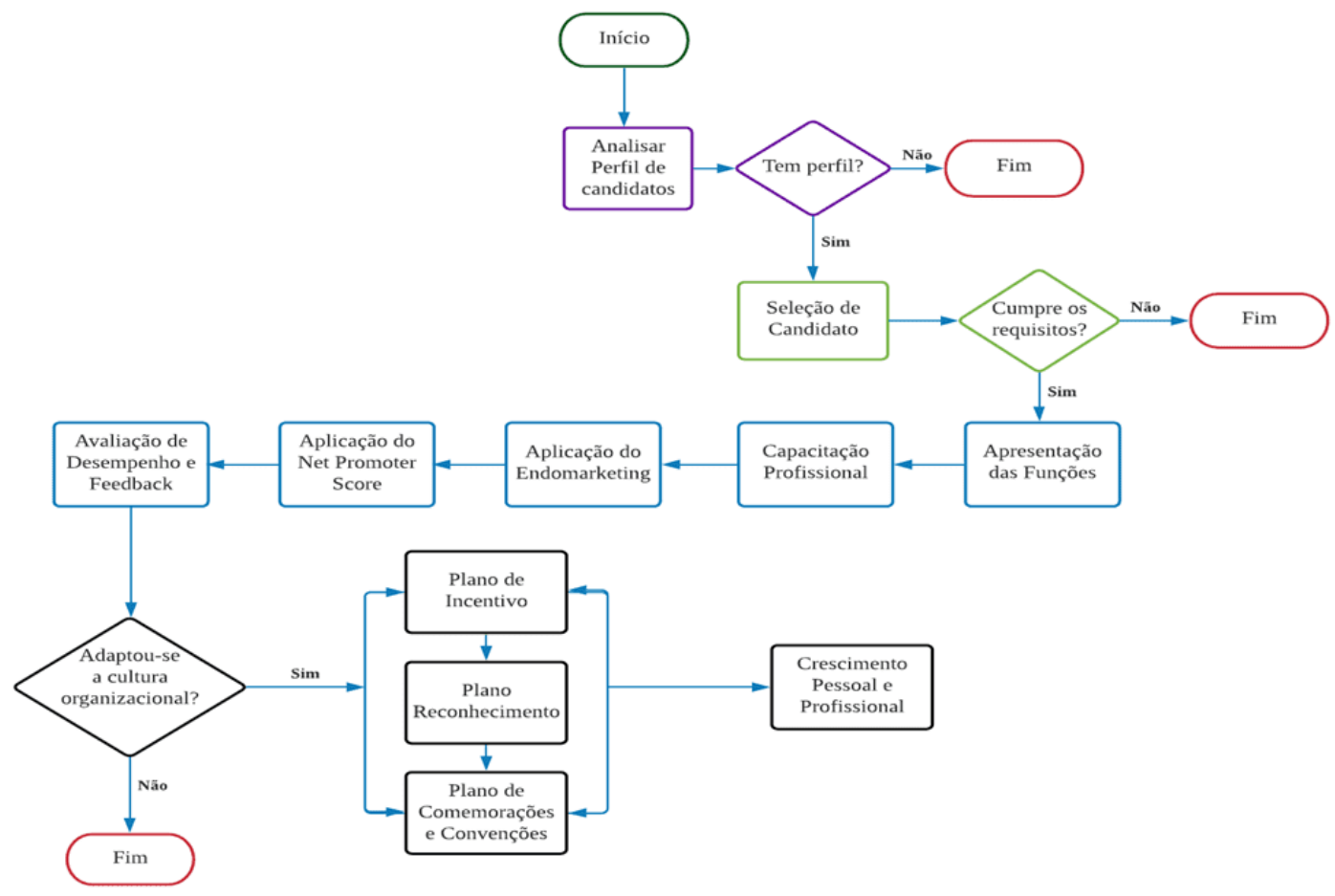

Fonte: Elaborado pelos autores, 2020.

\section{CONSIDERAÇÕES FINAIS}

Considerando o que foi exposto, se torna indispensável que as organizações busquem motivar seus funcionários de forma a satisfazer as necessidades intrínsecas e extrínsecas para que os mesmos tenham a sensação de valorização. Somente assim conseguirá colaboradores motivados, apresentando uma boa produtividade, sem 
absenteísmo e minimizando assim rotatividade nos cargos. Existem diversas formas ou ferramentas possíveis de motivar o colaborador e que têm como objetivo solucionar a problemática em que a empresa se encontra como: redução de seus lucros devidos a ausência e/ou falta daquele profissional qualificado devido à desmotivação, sensação de desigualdade ou falta de capacitação profissional.

Portanto diante do estudo de caso, os problemas encontrados no Restaurante Palhoça Ltda, correspondentes a área de Recursos Humanos, grande parte dos colaboradores estão insatisfeitos com a empresa refletindo diretamente na qualidade do atendimento prestado pelos colaboradores, a políticas motivacionais é imprescindível e que sejam aplicada de forma assertiva dentro da organização, a motivação se tornar um facilitador para criar um modelo de comprometimento do colaborador com a empresa através de métodos motivacionais, possibilitando assim que estes colaboradores desenvolvam suas competências e habilidades em prol da empresa como alguns exemplos que foram aplicados: Elaboração do plano de capacitação profissional, Implantação de ferramentas do Endomarketing, Implementação do plano de incentivos e reconhecimento, Implementação de comemorações e convenções, Implementação da avaliação do desempenho e repasse do feedback e Implementação do Net Promoter Score.

Os resultados apontados nesta pesquisa não podem ser generalizados e aplicados em outras empresas, pois cada uma possui sua peculiaridade e realidade de funcionamento a ser estudada. Conclui-se que estar motivado é de fundamental importância para o bom andamento da organização, para a relação favorável dos colaboradores com o gestor, como também para o empenho e contribuição dos funcionários no dia a dia de trabalho. Assim, a prática da motivação sobre os seus colaboradores internos é a única maneira de uma organização encarar à concorrência, sem que a mesma perca os seus talentos. Pois através da motivação os funcionários se tornaram fiéis e produtivos. 


\section{REFERÊNCIAS}

AZEVEDO, R. A. Revisão de Literatura, Referencial Teórico, Fundamentação Teórica e Framework Conceitual em Pesquisa - diferenças e propósitos. Workingpaper,

2016.Disponível:<https://unisinos.academia.edu/DeboraAzevedo/Papers> Acesso em 25 de set. de 2020 .

BATEMAN, Sneil Thomas. Administração 2o Edição. AMGH Ltda, 2012.

BUENO, Barbará Mariane Aparecida. Endomarketing: Uma ferramenta estratégica de gestão. FEMMA - ASSIS, 2013.

BUSARELLO, Raul. I. Gamificação: princípios e estratégias. São Paulo:Pimenta Cultura, 2016.

CAUCHICK, P. et. al. Metodologia de Pesquisa em Engenharia de Produções:2.ed.Rio de Janeiro:Elsevier:ABEPRO,2012.

CIOFFI, José Leandro. Remuneração Estratégia:1.ed.Rio de Janeiro:Seses,2016.

CORRÊA, Júlio César da Silva; COSTA, Marilia de Melo. Metodologia da pesquisa 1 e 2. Belém: IEPA, 2012.

DAHER, Ricardo Oliveira. Produtividade em foco: Engenharia a Serviço da Gestão. Editora NATTHEUS, 2017.

JONES, Gareth. R; GEORGE, Jennifer. M. Fundamentos da Administração Contemporânea: 4.ed. Porto Alegre. AMGH,2012.

LARA, José Edson et al. Net Promoter Score: Aplicação no Relacionamento com Clientes de Alta Renda na CAIXA - uma Instituição Financeira Pública Brasileira. 2016. Disponível em: <https://singep.org.br>. Acesso em: 28 de setembro de 2020.

LIBÓRIO, D; TERRA, L. Metodologia Científica: São Paulo, Copyright,2015. 
MARANGONI, Suzana Márcia. Marketing de Serviços 1ํe. ed. SESES, 2015.

PEREIRA, A. et. al. Metodologia da Pesquisa Científica:1.ed.Santa Maria, RS:UFSM, NTE,2018.

PONTES, Benedito Rodrigues. Avaliação de desempenho - Métodos clássico e contemporâneo, avaliação por objetivo, competência e equipes. 13.ed.Editora Ltda, 2016.

VERGARA, Sylvia Constant. Projeto e Relatório de Pesquisa em Administração:16.ed.São Paulo.Editora:Atlas,2016.

WAGNER, John A; HOLLENBECK, John R. Comportamento Organizacional: 4.ed.São Paulo: Saraiva Educação,2020.

Enviado: Outubro, 2020.

Aprovado: Novembro, 2020. 